Pediatrics

\title{
A staged approach to address youth unresponsive to initial obesity intervention: a randomized clinical trial
}

\author{
Katherine R. Arlinghaus $\mathbb{D}^{1 凶}$, Daniel P. O'Connor ${ }^{2}$, Tracey A. Ledoux ${ }^{2}$, Sheryl O. Hughes $\mathbb{D}^{3}$ and Craig A. Johnston ${ }^{2}$
}

๑) The Author(s), under exclusive licence to Springer Nature Limited 2021

BACKGROUND/OBJECTIVE: Maintenance interventions inherently require BMI improvement to maintain. This overlooks individuals initially unresponsive to obesity interventions. Staged pediatric clinical treatment guidelines were adapted to the school setting to develop an escalated treatment option for individuals initially unresponsive. This staged randomized controlled trial examined differences between escalated treatment (Take CHARGE!) and a maintenance program (PE Planners). Take CHARGE was hypothesized to have greater improvements in BMI as a percentage of the 95th BMI Percentile (\%BMIp95) than PE Planners. SUBJECTS/METHODS: From 2018 to 2020, 171 middle and high schoolers (BMI Percentile $\geq 85$ ) were recruited from a Houston school district to participate in a staged obesity intervention in their physical education (PE) class. After receiving a semester-long intensive lifestyle intervention (ILI) with established efficacy, all participants were randomized to Take CHARGE $(n=85)$ or PE Planners $(n=86)$. Take CHARGE escalated the behavioral treatment of obesity received in ILI with more frequent individual sessions, additional opportunities for parental and school staff involvement, and increased mentorship from trained college students. PE Planners allowed participants to decide how they wanted to be active in PE class. Mixed linear modeling examined \% BMIp95 overtime between groups. This trial was registered at ClinicalTrials.gov (\#NCT04362280).

RESULTS: Participants were $13.63 \pm 1.32$ years old; $59 \%$ were female, and $85 \%$ were Hispanic. Among those initially unresponsive to ILI, Take CHARGE had significantly greater decreases in \%BMIp95 than PE Planners $(\beta=-0.01, p<0.01)$. Conversely, among those initially responsive, Take CHARGE had significantly smaller decreases in \%BMlp95 than PE Planners $(\beta=0.02, p<0.05)$. Intention-totreat analysis had similar results.

CONCLUSIONS: Participant outcomes in semester two differed based on initial response. Individuals responsive to initial intervention were most likely to benefit from a maintenance intervention and those initially unresponsive benefited more from escalated treatment. This indicates the need for staged intervention protocols to better address obesity in the school setting.

International Journal of Obesity (2021) 45:2585-2590; https://doi.org/10.1038/s41366-021-00940-0

\section{INTRODUCTION}

Childhood obesity has reached epidemic proportions, and lowincome, ethnic minority children carry a disproportionate share of the obesity burden [1, 2]. Schools are important community settings to decrease health disparities because they provide reach to marginalized youth populations who are unlikely to seek medical care for obesity [3-6]. Behavioral school-based obesity interventions can result in greater mean improvements than control in the short term [7-9], but maintenance past 2 years is rare [10-14]. As a result, interest in pediatric maintenance intervention has grown [15]. While this shift toward long-term maintenance outcomes is important [16], it overlooks individuals who do not improve initially [17-20]. The factor most consistently associated with long-term response is initial response, and those unresponsive initially are unlikely to respond later in the intervention [21]. Therefore, it is important to identify treatment options for individuals who do not initially respond to intervention.

In a clinical setting, a staged algorithm is followed for obesity treatment in which treatment is escalated when individuals do not respond [22]. However, escalated treatment options do not exist for school-based interventions. The purpose of this study was to evaluate a staged school-based obesity treatment model for lowincome, ethnic minority youth. This study builds from an established school-based intensive lifestyle intervention (ILI) that has repeatedly been shown to reduce mean standardized BMI (zBMI) significantly more than control among this population. Following an academic semester ( 3 months) of this ILI, participants were randomized to receive either an escalated treatment (Take CHARGE!) or a maintenance condition (PE Planners). Due to evidence suggesting greater reductions in weight-related outcomes with more intensive, longer duration

\footnotetext{
${ }^{1}$ Division of Epidemiology and Community Health, School of Public Health, University of Minnesota, Minneapolis, MN, USA. ${ }^{2}$ Department of Health and Human Performance, University of Houston, Houston, TX, USA. ${ }^{3}$ Department of Pediatrics \& USDA ARS Children's Nutrition Research Center, Baylor College of Medicine, Houston, TX, USA.

然ail: karlingh@umn.edu
} 
interventions [17], it was hypothesized that students who received Take CHARGE in the second semester would have significantly greater mean reductions in BMI represented as a percentage of the 95th BMI Percentile (\%BMIp95) than students who were randomized to PE Planners.

\section{SUBJECTS AND METHODS Participants}

Students (grades 6-12) were recruited from a charter school district in Houston, Texas to participate in an academic year-long healthy lifestyles program during their physical education (PE) class. The study included two cohorts, 2018-2019 and 2019-2020. The school meets the federal Community Eligibility Provision, such that all students are provided free meals at school. Study inclusion criteria included enrollment in PE class and being 10-17 years old. Students were excluded from the study if they were or became pregnant, had a cognitive or physical limitation that prevented them from participating in intervention activities, or were absent from class for more than 5 consecutive days. Although students of all weight classifications were invited to participate in this study, only those with a BMI Percentile $\geq 85$ th percentile were included in this analysis. The flow of participants is outlined in Fig. 1. A power analysis with alpha $=0.05$ and beta $=0.20$ indicated that a sample size of 152 (76 in each group) was adequate to detect a 0.10 difference in standardized BMI between groups, which is consistent with effect size typically found in school-based obesity interventions [7-9]. This study was approved by the University of Houston Institutional Review Board. All participants provided written parent consent and child assent.

\section{Intervention procedures}

Initial intensive lifestyle intervention and randomization. During the first academic semester, all participants received an ILI with established efficacy among this population [23-25]. Briefly, ILI was based on Social Cognitive Theory (SCT) and occurred as students' PE class 5 days/week. Intervention activities included 1 day of nutrition education and 4 days of physical activity with behavioral modification techniques overlaid throughout. Trained undergraduate students performed intervention activities with participants (one undergraduate per 30 participants). Parents were invited to monthly after-school educational sessions.

Following $\mathrm{ILI}$, the principal investigator randomized participants to Take CHARGE or PE Planners using a random numbers table and a 1:1 allocation. Students and research staff were not blinded to the condition. Both study arms occurred during participants' PE class, 5 days/week for 45 min each day for 3 months. All participants wore heart rate monitors and were

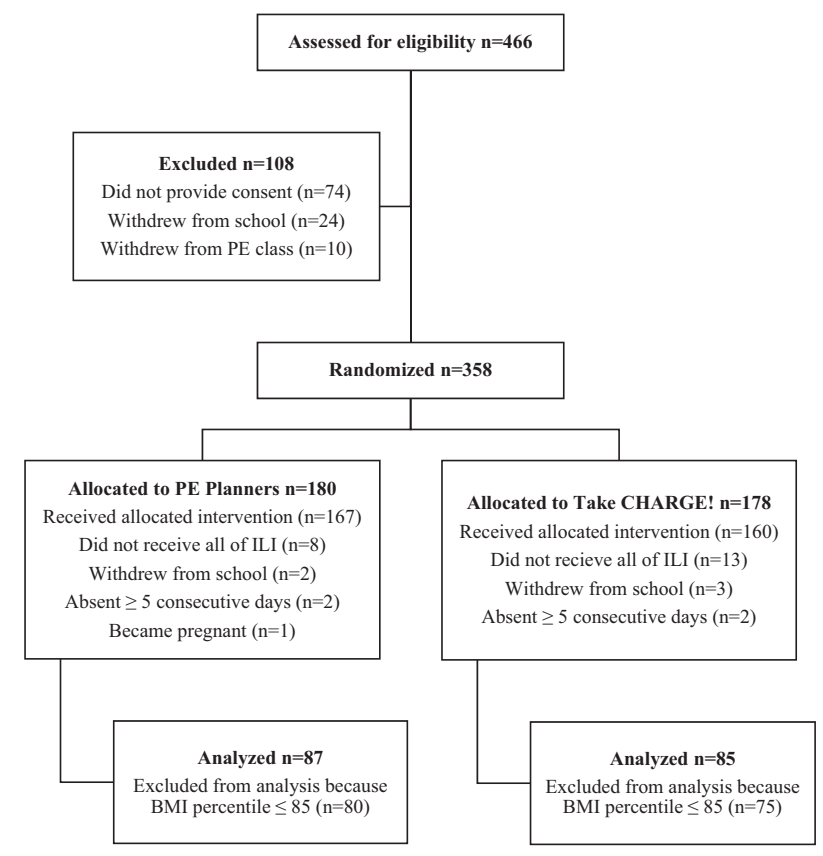

Fig. 1 Flow diagram of participants' progress through each study phase. graded based on the number of minutes they spent in their individual target heart rate zone.

Intervention arm 1: Take CHARGE!. Take CHARGE! stands for Teens Committed to Health through Activity, Relationships, and Good Eating. Like ILI, Take CHARGE was based on SCT $[26,27]$ and designed to increase social and environmental supports for behavior change. The escalation in treatment from ILI in the first semester to Take CHARGE in the second semester parallels the transition from structured weight management (SWM) to comprehensive multidisciplinary intervention (CMI) in the clinical algorithm for pediatric obesity treatment [22]. Compared to SWM, progress monitoring in CMI is conducted more frequently. In addition, an expanded, multidisciplinary care team is created in CMI with greater parental involvement and the inclusion of additional medical professionals.

Take CHARGE followed the same principles as CMI in the school setting. Weight was measured and graphed weekly. Students met with a registered dietitian and were asked to reflect on how physical activity and dietary behaviors over the last week may have contributed to a change in weight. Participants monitored dietary consumption with food logs. Sleep was monitored with a Polar 300 watch and self-report sleep logs, and physical activity was monitored with the step count on Polar 300 watches. Homework assignments were designed to promote self-monitoring.

An increased medical care team was mimicked in the school setting with family teams, increased school staff involvement, and increased parental involvement. Participants were grouped into family teams of six to eight classmates, each led by a trained undergraduate. Participants created goals with family leaders who assisted them in monitoring goal progress, modeled intervention activities, and ate school lunch with participants weekly. Competitions between families were held to promote healthy behaviors and self-monitoring. School staff were invited to participate in workouts, help judge cooking competitions, and assist with family-based rewards. Like a medical care team, researchers had weekly meetings with school staff about individual student progress. School staff provided additional support for healthy behavior changes outside of PE class to students who were gaining weight.

Multiple parental involvement opportunities were provided. Weekly text messages were sent to parents about class topics and offered suggestions on ways to support their child at home. Individual health screeners (i.e., a BMI report card) were sent home with participants. This screener described the participant's progress during ILI. It indicated the individual participant's weight classification and provided resources and actionable steps regarding healthy behaviors at home. A registered dietitian called parents to ensure receipt of the health screener, answer questions, and invite parents to participate in a nutrition counseling session. Lastly, 1 day/week female and male participants completed intervention activities separately from each other. This day provided an opportunity to discuss issues such as body image and to exercise only among same-sex peers.

Intervention arm 2: PE planners (PE planners). Participants in PE Planners planned what they would do in PE. PE teachers approved plans based on feasibility and safety. Every 2 weeks, students used reports of their daily time in their target heart rate zone from the past 2 weeks to revise their plan for the next 2 weeks. PE teachers did not initiate support or provide instruction during workouts but did intervene if an activity was unsafe or if a student was at risk of failing the course. Homework consisted of sports education readings with comprehension questions. All PE Planners sessions were co-ed. No attempts at parental involvement were made. Outside school staff was not enlisted for support and undergraduates had no contact with PE Planners participants.

\section{Measures}

Prior to beginning ILI, participants completed a demographic questionnaire. Intervention attendance was recorded daily. Height and weight were directly measured by trained research staff before and after ILI and after the second semester intervention. Participants' height and weight were measured in minimal clothing and without shoes to the nearest 0.1 centimeter and kilogram respectively. BMI, BMI Percentile, standardized $\mathrm{BMI}$, and \%BMIp95 were calculated according to the CDC guidelines. Due to the high prevalence of severe obesity among study participants, \% BMIp95 was chosen over other weight-related metrics as the primary outcome metric for this analysis [28].

Dose of intervention received was assessed as the number of days participants attended the intervention sessions (i.e., PE class) each semester. This information was calculated from prospectively collected 
Table 1. Short-term response guidelines for school-based obesity intervention ${ }^{\mathrm{a}}$.

\begin{tabular}{|c|c|c|}
\hline Age & $\begin{array}{l}\text { Baseline BMI } \\
\text { percentile }\end{array}$ & Response at 3 months \\
\hline \multirow[t]{5}{*}{11 or younger } & $<5$ th & Gradual weight gain \\
\hline & $\geq 5$ th and $<85$ th & $\begin{array}{l}\text { Maintain or decrease BMI } \\
\text { Percentile }\end{array}$ \\
\hline & $\geq 85$ th and $<95$ th & $\begin{array}{l}\text { Maintain or decrease } \\
\text { weight gradually }\end{array}$ \\
\hline & $\geq 95$ th and <99th & Gradual weight loss \\
\hline & $\geq 99$ th & Weight loss \\
\hline \multirow[t]{4}{*}{12 or older } & $<5$ th & Gradual weight gain \\
\hline & $\geq 5$ th and $<85$ th & $\begin{array}{l}\text { Maintain or decrease BMI } \\
\text { Percentile }\end{array}$ \\
\hline & $\geq 85$ th and $<95$ th & $\begin{array}{l}\text { Maintain or decrease } \\
\text { weight gradually }\end{array}$ \\
\hline & $\geq 95$ th & Weight loss \\
\hline
\end{tabular}

${ }^{a}$ Adapted from AAP Recommendations for Treatment of Child and Adolescent Overweight and Obesity [22, 23].

attendance records for each participant. Dose was transformed to be mean-centered. Response to ILI in the first academic semester and response to second semester treatment were determined based on the American Academy of Pediatrics (AAP) guidelines childhood obesity treatment [22], which were adapted for the school setting (Table 1).

Statistical analysis. Statistical analysis was conducted with SPSS 26. Means and prevalence of demographic characteristics were computed. Changes in weight-related metrics in the first semester were calculated. A two by one repeated measures ANOVA was calculated to examine \%BMIp95 over the first semester. Chi-square and $t$-tests evaluated demographic and anthropometric differences between study arms at the time of randomization.

Mixed linear models (restricted maximum likelihood estimation) with random intercepts to account for the repeated measures of each subject and time-varying covariates (i.e., dose) were developed to evaluate the differences in \%BMlp95 over the course of the second semester between treatment arms (i.e., Take CHARGE and PE Planners) and between treatment arms considering response to ILI in the first semester (i.e., initially unresponsive Take CHARGE, initially responsive Take CHARGE, initially unresponsive PE Planners, initially responsive PE Planners). Fixed effects in the models included the class period in which participants received intervention (unique to their cohort), time (continuous), meancentered dose, group, time*dose, and time ${ }^{*}$ group. Due to the expected difference in dose between cohorts (cohort 2 received fewer days of intervention than cohort 1 because of COVID-19 related school closures), two mixed linear models were developed, one with dose centered at the mean dose of cohort 1 and one with dose centered at the mean dose of cohort 2. This allowed for evaluating the average responses in each cohort. Consistent with CONSORT Guidelines, an intention-to-treat model was developed using the last observation carried forward method. Lastly, the proportion of responsive participants were compared between treatment arms using a chi-square test.

\section{RESULTS}

Table 2 shows demographic and anthropometric characteristics of individuals at the time of randomization. There were no differences between treatment arms at the time of randomization or between those who completed the intervention and those who did not. No adverse effects of intervention were reported by participants. Changes in weight-related outcomes over the first semester were similar to prior implementation of ILI [23] (Table 2). The within group change in \%BMlp95 during the first semester was statistically significant $(F(1,170)=19.89 ; p<0.001)$.
Table 2. Demographic and anthropometric characteristics, Mean (SD) or $n[\%]$.

\begin{tabular}{|c|c|c|c|}
\hline Characteristic & $\begin{array}{l}\text { Overall } \\
(n=171)\end{array}$ & $\begin{array}{l}\text { Take CHARGE } \\
(n=85)\end{array}$ & $\begin{array}{l}\text { PE Planners } \\
(n=86)\end{array}$ \\
\hline \multicolumn{4}{|c|}{ Demographic characteristics } \\
\hline Age & $13.63(1.32)$ & $13.64(1.28)$ & $13.62(1.36)$ \\
\hline \multicolumn{4}{|l|}{ Sex } \\
\hline Male & 70 [40.94] & $36[42.35]$ & 34 [39.53] \\
\hline Female & $101[59.06]$ & $49[57.65]$ & $52[60.47]$ \\
\hline \multicolumn{4}{|l|}{ Ethnicity } \\
\hline Hispanic & $146[85.38]$ & $72[84.70]$ & $74[86.05]$ \\
\hline African American & 24 [14.04] & $12[14.12]$ & 12 [13.95] \\
\hline Asian & $1[0.58]$ & $1[1.18]$ & $0[0.00]$ \\
\hline \multicolumn{4}{|c|}{ Anthropometric changes in first academic semester (post ILI - pre-ILI) } \\
\hline Height change $(\mathrm{cm})$ & $0.90(0.89)$ & $0.96(0.95)$ & $0.85(0.84)$ \\
\hline Weight change (kg) & $0.59(2.19)$ & $0.59(2.28)$ & $0.58(2.11)$ \\
\hline BMI change & $-0.09(0.85)$ & $-0.10(0.85)$ & $-0.06(0.95)$ \\
\hline $\begin{array}{l}\text { BMI } \\
\text { Percentile change }\end{array}$ & $-0.33(1.65)$ & $-0.30(1.59)$ & $-0.35(1.71)$ \\
\hline $\begin{array}{l}\text { Standardized } \\
\text { BMI change }\end{array}$ & $-0.04(0.11)$ & $-0.04(0.10)$ & $-0.04(0.11)$ \\
\hline \%BMlp95 change & $-1.35(3.23)$ & $-1.45(3.21)$ & $-1.25(3.27)$ \\
\hline \multicolumn{4}{|l|}{ Response to ILI ${ }^{\mathrm{a}}$} \\
\hline Responsive & $59[34.50]$ & 27 [31.76] & $32[37.21]$ \\
\hline Unresponsive & $112[65.50]$ & 58 [68.24] & 54 [62.79] \\
\hline \multicolumn{4}{|c|}{ Anthropometric characteristics at randomization (start of second semester) } \\
\hline Height (cm) & $158.06(8.78)$ & $158.50(9.36)$ & $157.62(8.19)$ \\
\hline Weight (kg) & $70.87(16.52)$ & $71.65(16.74)$ & $70.10(16.35)$ \\
\hline BMI & $28.14(4.86)$ & $28.32(5.08)$ & $27.95(4.65)$ \\
\hline BMI Percentile & $94.58(4.21)$ & $94.62(4.31)$ & $94.55(4.14)$ \\
\hline Standardized BMI & $1.76(0.46)$ & $1.77(0.47)$ & $1.74(0.44)$ \\
\hline \%BMIp95 & 106.92 (17.86) & $107.65(18.70)$ & 106.19 (17.07) \\
\hline \multicolumn{4}{|l|}{ Weight classification } \\
\hline Overweight & 74 [43.27] & 36 [42.35] & 38 [44.19] \\
\hline Moderate obesity & 61 [35.67] & 30 [35.29] & 31 [36.05] \\
\hline Severe obesity & $36[21.05]$ & 19 [22.35] & 17 [19.77] \\
\hline
\end{tabular}

ILI Intensive Lifestyle Intervention.

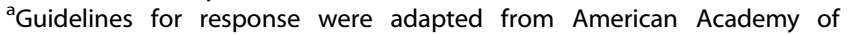
Pediatrics guidelines for childhood obesity treatment and are specifically outlined in Table 1 [16].

\section{Evaluation of semester two intervention}

Both groups decreased \%BMlp95 over the course of the second semester (dose centered on cohort 1 mean: $F(1,168.01)=47.15$, $p<0.001$; dose centered on cohort 2 mean: $F(1,168.01)=6.20, p<$ $0.05)$. There were no differences in \%BMlp95 between groups over the course of the second semester (both models: $F(1,168.16)=$ $0.28, p=0.60$ ). However, a significant interaction effect of time*group was found when response to ILI in the first semester was considered (both models: $F(3,166.14)=5.00, p<0.01$ ) (Fig. 2). Among those unresponsive to ILI, those in Take CHARGE had a significantly greater decrease in \%BMIp95 than those in $\mathrm{PE}$ Planners (both models: $\beta=-0.01, t=-2.52, p<0.01$ ). Conversely, among those responsive to ILI, those in Take CHARGE had significantly smaller decreases in \%BMIp95 than those in PE Planners (both models: $\beta=0.02, t=2.31, p<0.05$ ). Estimated mean changes across various anthropometric measures during the second semester and over the academic year are provided in Table 3 to enable the interpretation of the magnitude of change seen in each group. Mean changes were estimated with time based on days in cohort 1 and dose centered on cohort 1 mean. 
The time*dose interaction was significant in the models comparing randomization groups $(F(1,168.01)=5.12, p<0.05)$ and in the models comparing groups with consideration of response to ILI in the first semester $(F(1,166.01)=4.33 p<0.05)$. The slope of \%BMlp95 change over time was steeper for those who received a higher dose of either intervention. Irrespective of dose received, those unresponsive to ILI in Take CHARGE decreased \%BMIp95 on average, however those who received

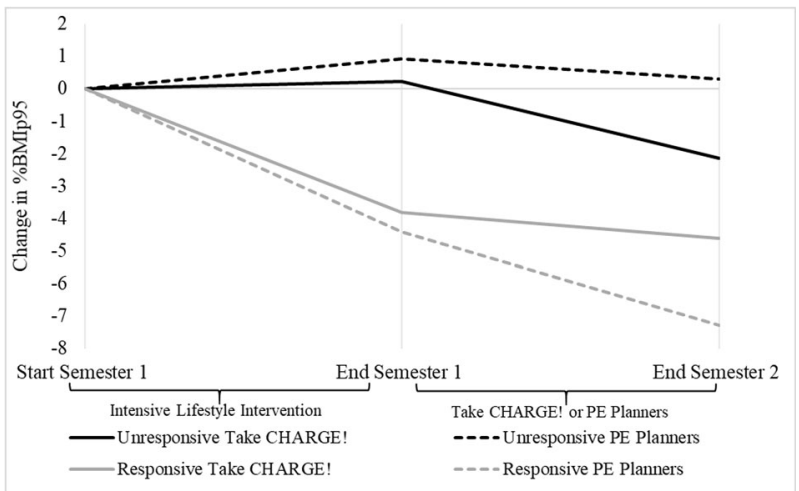

Fig. 2 Overall changes in \%BMIp95 considering response to ILI in the first semester. \%BMIp95 = BMI represented as a percentage of the 95th BMI Percentile. a high dose decreased \%BMlp95 faster than those with a low dose. Comparatively, the individuals unresponsive to ILI who received a low dose of PE Planners increased \%BMIp95; whereas those who received a high dose decreased \%BMIp95 (Supplementary Fig. 1).

\section{Evaluation of response}

There was no difference in the proportion of participants who were responsive in the second semester between treatment arms overall $\left(x^{2}(1, N=171)=0.07, p=0.79\right)$ or when considering response to ILI in the first semester $\left(X^{2}(3, N=171)=4.58, p=\right.$ 0.21). Among those in PE Planners, the proportion of participants responsive in the second semester was higher among those who were responsive to ILI in the first semester $\left(X^{2}(1, N=86)=3.95\right.$, $p<0.05$ ) (Fig. 3).

\section{Intention-to-treat analysis}

The primary results of the intention-to-treat models paralleled that of the completers models. There were no differences in \%BMlp95 between treatment arms over the course of the second semester (both models $F(1,177.16)=0.25, p=0.62$ ). A significant time*group interaction was found when response to ILI was considered $(F(3,175.14)=5.40, p<0.01)$. Among those unresponsive to ILI in the first semester, those in Take CHARGE had a significantly greater decrease in \%BMIp95 than those in PE Planners (both models: $\beta=-0.01, t=-2.68, p<0.01$ ). Among those responsive to ILI in the first semester, those in Take CHARGE had significantly

Table 3. Estimated mean changes in anthropometric measures over the second semester and the academic year by treatment group based on response to ILI in semester one, mean (SD) $N=171$.

\begin{tabular}{|c|c|c|c|c|c|c|c|c|}
\hline & \multicolumn{4}{|c|}{ Change during semester two } & \multicolumn{4}{|c|}{ Change over entire academic year } \\
\hline & \multicolumn{2}{|c|}{$\begin{array}{l}\text { Unresponsive to ILI first } \\
\text { semester }\end{array}$} & \multicolumn{2}{|c|}{$\begin{array}{l}\text { Responsive to ILI first } \\
\text { semester }\end{array}$} & \multicolumn{2}{|c|}{$\begin{array}{l}\text { Unresponsive to ILI first } \\
\text { semester }\end{array}$} & \multicolumn{2}{|c|}{$\begin{array}{l}\text { Responsive to ILI first } \\
\text { semester }\end{array}$} \\
\hline Height $(\mathrm{cm})$ & $1.46(0.14)$ & $1.64(0.18)$ & $0.72(0.03)$ & $1.45(0.15)$ & $2.63(0.22)$ & $2.54(0.21)$ & $1.21(0.04)$ & $2.27(0.17)$ \\
\hline BMI Percentile & $-0.95(0.26)$ & $-0.39(0.16)$ & $-0.37(0.15)$ & $-1.25(0.32)$ & $-0.84(0.04)$ & $-0.03(0.06)$ & $-1.67(0.14)$ & $-2.81(0.28)$ \\
\hline BMI Z-score & $-0.07(0.02)$ & $-0.02(0.02)$ & $-0.03(0.02)$ & $-0.11(0.03)$ & $-0.06(0.02)$ & $0.00(0.01)$ & $-0.16(0.03)$ & $-0.25(0.04)$ \\
\hline \%BMIp95 & $-2.16(0.92)$ & $-0.51(0.64)$ & $-0.89(0.68)$ & $-3.16(1.14)$ & $-2.30(0.91)$ & $0.14(0.64)$ & $-5.13(1.21)$ & $-7.60(1.56)$ \\
\hline
\end{tabular}

$\%$ BMIp95 $=$ BMI represented as a percentage of the 95th BMI Percentile.

ILI Intensive lifestyle intervention.

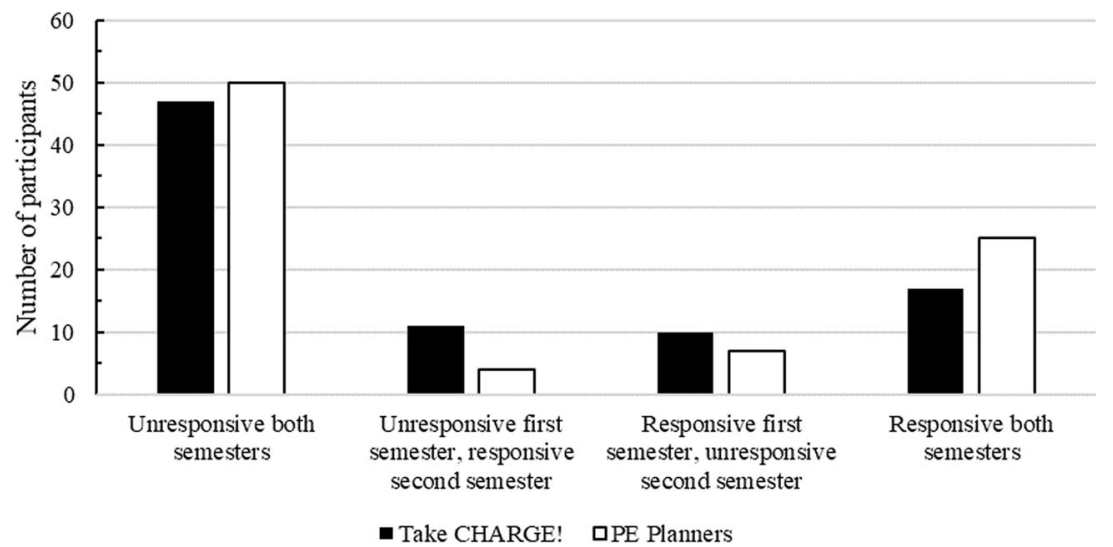

Fig. 3 Proportion of participants responsive over the academic year. Guidelines for response were adapted from American Academy of Pediatrics guidelines for childhood obesity treatment and are specifically outlined in Table 1 [16]. 
smaller decreases in \%BMIp95 than those in PE Planners (both models: $\beta=0.02, t=2.63, p<0.01)$. In contrast to the completers model which found no main effect for either period or dose, the main effects for both period $(F(8,167.00)=2.34, p<0.05)$ and dose $(F(1,168.23)=12.01, P<0.01)$ were statistically significant (Supplementary Table 1).

\section{DISCUSSION}

This study was the first to evaluate a stepped obesity treatment in the school setting. Consistent with the hypothesis, participants unresponsive to ILI who received Take CHARGE had greater improvement in \%BMIp95 than those in PE Planners. In contrast to the hypothesis, those responsive to ILI who received PE Planners had significantly greater \%BMlp95 improvement than those in Take CHARGE. Together, these results illustrate the importance of secondary intervention options and the value in considering an individual's response to initial treatment when providing secondary intervention. The results of this study among individuals unresponsive to ILI are consistent with findings among adults in which providing stepped care has resulted in improved weight outcomes for some individuals, but not for others [29].

While those unresponsive to ILI in the first semester experienced significantly greater mean improvements in \%BMIp95 in Take CHARGE compared to PE Planners, many participants who were unresponsive to ILI were also unresponsive to Take CHARGE. This group of unresponsive individuals represent a high-risk population in need of a different treatment option. According to clinical guidelines, the next stage of treatment for individuals unresponsive to CMI is tertiary care (i.e., pharmaceutical and surgical options) [22]. This study took initial steps to understanding the limits of schoolbased intervention. Additional research is necessary to identify when treatment needs to be transitioned outside the school setting. Many school-based interventions are designed to prevent, not necessarily treat, obesity [22]. The results of this study indicate that schools can play a multi-staged role in the treatment of obesity. Given the growing prevalence of severe obesity among adolescents for whom prevention efforts alone are unlikely to have a meaningful impact [1], it is important to consider the role of schools in treatment in the creation of clinic-school partnerships.

This study indicated that providing escalated treatment to individuals initially responsive may be detrimental to weight outcomes. SCT postulates a dynamic interplay between the individual, environment, and behavior $[26,27]$. However, it is unclear the degree to which various aspects of the environment and an individual's past experiences contribute to behavioral changes. Past experiences with intervention may be relevant regarding response to secondary intervention, and possibly more important than supports provided in secondary intervention. A main tenant of SCT is the importance of outcome expectancies [26]. It is possible that providing escalated treatment to participants who were responsive to ILI contradicted participants' outcome expectancies, which are likely to be consistent with their expectations for other classes. When a student does well in an academic subject they are positively reinforced with a good grade and usually given greater autonomy. As teachers often provide additional attention to students who are misbehaving or not performing well academically, additional attention that is not framed as a reward or recognition of good work might be considered negative reinforcement. The experience of Take CHARGE participants who were responsive to ILI may be inconsistent with their outcome expectancies. Instead of being given greater autonomy as potentially expected, these students were given less autonomy and received increased attention from teachers and research staff. These findings indicate the importance of considering appropriate reinforcements for each treatment stage and the need to develop appropriate participant expectations at each stage.
Improvements among participants initially responsive to ILI in PE Planners may provide insight into the role of physical activity among youth for weight maintenance. Although participants were allowed, zero participants included nutrition education in their plans. Therefore, PE Planners participants solely focused on physical activity in class. Findings among this subsample are consistent with the established importance of physical activity in weight maintenance among adults [30]. However, unlike adults among whom physical activity generally helps maintain but not necessarily lose weight [31], participants in this subsample decreased-not just maintained-\%BMlp95. For pediatric populations maintaining weight during growth results in an improvement in BMI. This illustrates the potential for maintenance programs to result in continued improvement in BMI among youth and provides an important rationale for pediatric maintenance intervention.

Among initially unresponsive individuals a minimal dose of Take CHARGE was more beneficial than a minimal dose of PE Planners. While there was no control condition in this study, a minimal dose of PE Planners is indicative of receiving little structured intervention. Individuals who were unresponsive initially in PE Planners increased \%BMIp95 while those who received a low dose of Take CHARGE still improved \%BMIp95. This illustrates that there may be benefit for unresponsive individuals to receive even a small dose of intensive intervention. This is an important finding as students at highest risk of being unresponsive may also be at increased risk for poor school attendance [32].

As illustrated by the estimated mean changes provided in Table 3 , those who were unresponsive to ILI in the first semester were unlikely to reach a clinically meaningful level of improvement by the end of the academic year, even when provided the escalated Take CHARGE intervention. However, unlike those initially responsive who experienced most of their improvement in the first semester, participants initially unresponsive experienced the majority of improvement in \%BMlp95 during the second semester. Although unable to identify a specific threshold of weight improvement associated with cardiometabolic improvements, the United States Preventive Task Force generally agreed with European researchers that a $0.20-0.25$ reduction in standardized $\mathrm{BMI}$ is likely to have meaningful health benefits for youth [17]. On average, only those participants who responded to ILI initially and received PE Planners in the second semester were estimated to reach this level of improvement. As initially responsive participants who were in Take CHARGE were not estimated to reach this level of improvement, the results of this study demonstrate the importance of assessing initial response not just to identify better options for those initially unresponsive, but to also identify better options for those who are responsive initially.

Overall, mean improvements among all groups except those initially unresponsive who received PE Planners were as larger or larger than improvements seen in behavioral adolescent weight loss interventions provided in clinical settings to treatmentseeking populations [33]. Participants in this study were not actively seeking treatment for obesity. With one in every five adolescents having obesity in America and many barriers to obesity care, the results of this study illustrate the potential role for providing behavioral treatment, not just prevention, of obesity in the school setting.

This study contributed to the literature by adapting clinical guidelines to investigate the effectiveness of a staged approach to treatment in the school setting. Being in the school environment made it infeasible to conduct a blinded randomized controlled trial, which likely introduced bias. Although statistical analysis was conservatively conducted to account for differences in intervention dose received due to school closures for the COVID-19 pandemic, it is possible that this could have impacted study results. It is also possible that outcomes may be influenced by participant's pubertal maturation. Unfortunately, this was not 
assessed in the study to include in the models. Generalizability is limited by the relatively homogenous study sample, but this study's framework can be applied to other schools.

This study created one of the first escalated treatment options for individuals unresponsive to initial school-based treatment. The staged framework developed through this study can be used to refine intervention content. The findings of this study illustrate the need to consider response to initial intervention as a determinant of appropriate secondary intervention. Understanding response to initial intervention can help improve overall outcomes for participants.

\section{REFERENCES}

1. Ogden $\mathrm{CL}$, Carroll MD, Lawman HG, Fryar CD, Kruszon-Moran D, Kit BK, et al. Trends in obesity prevalence among children and adolescents in the United States, 1988-1994 through 2013-2014. JAMA. 2016;315:2292-9.

2. Ogden CL, Carroll MD, Fakhouri TH, Hales CM, Fryar CD, Li X, et al. Prevalence of obesity among youths by household income and education level of head of household - United States 2011-2014. MMWR Morb Mortal Wkly Rep. 2018;67:186-9.

3. Kropski JA, Keckley PH, Jensen GL. School-based obesity prevention programs: An evidence-based review. Obesity. 2008;16:1009-18.

4. Zenzen W, Kridli S. Integrative review of school-based childhood obesity prevention programs. J Pediatr Health Care. 2009;23:242-58.

5. Davidson JA, Kannel WB, Lopez-Candales A, Morales L, Moreno PR, Ovalle F, et al. Avoiding the looming Latino/Hispanic cardiovascular health crisis: a call to action. J Cardiometab Syndr. 2007:2:238-43.

6. Committee on Accelerating Progress in Obesity Prevention, Food and Nutrition Board, Institute of Medicine. Accelerating progress in obesity prevention: Solving the weight of the nation. Washington (DC): National Academies Press (US); 2012.

7. Ho M, Garnett SP, Baur L, Burrows T, Stewart L, Neve M, et al. Effectiveness of lifestyle interventions in child obesity: systematic review with meta-analysis. Pediatrics. 2012;130:e1647-e1671.

8. Al-Khudairy L, Loveman E, Colquitt JL, Mead E, Johnson RE, Fraser H, et al. Diet, physical activity and behavioural interventions for the treatment of overweight or obese adolescents aged 12 to 17 years. Cochrane Database Syst Rev. 2017;6: Cd012691.

9. Wang Y, Cai L, Wu Y, Wilson RF, Weston C, Fawole $O$, et al. What childhood obesity prevention programmes work? A systematic review and meta-analysis. Obes Rev. 2015;16:547-65.

10. Danielzik S, Pust S, Müller MJ. School-based interventions to prevent overweight and obesity in prepubertal children: process and 4-years outcome evaluation of the Kiel Obesity Prevention Study (KOPS). Acta Paediatr. 2007;96:19-25.

11. Kafatos A, Manios $Y$, Moschandreas J. Health and nutrition education in primary schools of Crete: follow-up changes in body mass index and overweight status. Eur J Clin Nutr. 2005;59:1090-2.

12. James J, Thomas P, Kerr D. Preventing childhood obesity: two year follow-up results from the Christchurch obesity prevention programme in schools (CHOPPS). BMJ. 2007;335:762.

13. Jurak G, Cooper A, Leskosek B, Kovac M. Long-term effects of 4-year longitudinal school-based physical activity intervention on the physical fitness of children and youth during 7-year followup assessment. Cent Eur J Public Health. 2013;21:190-5.

14. Manios $Y$, Kafatos $A$. Health and nutrition education in primary schools in Crete: 10 years follow-up of serum lipids, physical activity and macronutrient intake. $\mathrm{Br} J$ Nutr. 2006;95:568-75.

15. van der Heijden LB, Feskens EJM, Janse AJ. Maintenance interventions for overweight or obesity in children: a systematic review and meta-analysis. Obes Rev. 2018;19:798-809.

16. Jones RA, Sinn N, Campbell KJ, Hesketh K, Denney-Wilson E, Morgan PJ, et al. The importance of long-term follow-up in child and adolescent obesity prevention interventions. Int J Pediatr Obes. 2011;6:178-81.

17. O'Connor EA, Evans CV, Burda BU, Walsh ES, Eder M, Lozano P. Screening for obesity and intervention for weight management in children and adolescents: evidence report and systematic review for the US Preventive Services Task Force. JAMA. 2017;317:2427-44.
18. McBride CM, Bryan AD, Bray MS, Swan GE, Green ED. Health behavior change: can genomics improve behavioral adherence? Am J Public Health. 2012;102:401-5.

19. van Stralen MM, Yildirim M, te Velde SJ, Brug J, van Mechelen W, Chinapaw MJ. What works in school-based energy balance behaviour interventions and what does not? A systematic review of mediating mechanisms. Int J Obes. 2011:35:1251-65.

20. Freedman DS, Lawman HG, Galuska DA, Goodman AB, Berenson GS. Tracking and variability in childhood levels of BMI: the Bogalusa Heart Study. Obesity. 2018;26:1197-202.

21. Arlinghaus KR, O'Connor DP, Ledoux TA, Hughes SO, Johnston CA. The role of early response in school-based obesity intervention. Obesity. 2020;29:177-83.

22. Barlow SE. Expert committee recommendations regarding the prevention, assessment, and treatment of child and adolescent overweight and obesity: summary report. Pediatrics. 2007;120:S164-S192.

23. Johnston CA, Tyler C, Fullerton G, Poston WSC, Haddock CK, McFarlin B, et al. Results of an intensive school-based weight loss program with overweight Mexican American children. Int J Pediatr Obes. 2007;2:144-52.

24. Johnston CA, Tyler C, McFarlin BK, Poston WSC, Haddock CK, Reeves R, et al. Weight loss in overweight Mexican American children: a randomized, controlled trial. Pediatrics. 2007;120:e1450-e1457.

25. Johnston CA, Moreno JP. Development of a school-based obesity intervention for Mexican Americans. Clin Pract in Pediatr Psychol. 2014;2:116-30.

26. Bandura A. Health promotion by social cognitive means. Health Educ Behav. 2004;31:143-64.

27. Bandura A, (eds). Social Foundations of Thought and Action: A Social Cognitive Perspective. Englewood Cliffs, NY: Prentice-Hall; 1986.

28. Freedman DS, Berenson GS. Tracking of BMI z scores for severe obesity. Pediatrics. 2017;140:e20171072.

29. Carels RA, Young KM, Hinman N, Gumble A, Koball A, Wagner Oehlhof M, et al. Stepped-care in obesity treatment: matching treatment intensity to participant performance. Eat Behav. 2012;13:112-8.

30. Paixão C, Dias CM, Jorge R, Carraco EV, Yannakoulia M, de Zwann M, et al. Successful weight loss maintenance: a systematic review of weight control registries. Obes Rev. 2020;21:e13003.

31. Swift DL, McGee JE, Earnest CP, Carlisle E, Nygard M, Johannsen NM. The effects of exercise and physical activity on weight loss and maintenance. Prog Cardiovasc Dis. 2018;61:206-13.

32. An R, Yan H, Shi X, Yang Y. Childhood obesity and school absenteeism: a systematic review and meta-analysis. Obes Rev. 2017;18:1412-24.

33. Cardel MI, Atkinson MA, Taveras EM, Holm JC, Kelly AS. Obesity treatment among adolescents: a review of current evidence and future directions. JAMA Pediatr. 2020;174:609-17.

\section{AUTHOR CONTRIBUTIONS}

KRA conceived the study idea, led data collection and analysis, and drafted the initial paper. DPO and CAJ verified analytic methods, and CAJ supervised study implementation. DPO, TAL, SOH, and CAJ were involved in study planning and provided critical review of the paper.

\section{COMPETING INTERESTS}

The authors declare no competing interests.

\section{ADDITIONAL INFORMATION}

Supplementary information The online version contains supplementary material available at https://doi.org/10.1038/s41366-021-00940-0.

Correspondence and requests for materials should be addressed to K.R.A.

Reprints and permission information is available at http://www.nature.com/ reprints

Publisher's note Springer Nature remains neutral with regard to jurisdictional claims in published maps and institutional affiliations. 